\title{
Efficiency of warp knitted fabrics in cementitious composites
}

\begin{abstract}
Fabric-cement composites are one of the cementitious composites with high mechanical performance. The difference between the cement and polymer matrix is related to the interactions between the yarns and matrixes; in the cement matrix these interactions are more complex. The present paper explored the influence of two bar guides Marquisette and voil fabrics on the mechanical behavior of such composites. Different shape and size of the mesh of these fabrics were examined. It was found that the Marquisette fabric with square mesh exhibited the greatest efficiency in flexural performance but, voil fabrics showed higher toughness efficiency and rupture time. Finally, Marquisette structure with square mesh and higher weight which can be obtained by longer lapping movement in back guide bar was suggested as a suitable reinforcement for this kind of composites. However, Marquisette structure with three guide bars with similar mesh shape and size is probably presented more efficiency of flexural performance, higher toughness efficiency and rupture time.
\end{abstract}

Keywords: cement composites, voil fabric, marquisette fabric, composite performance, fabric structure, flexural efficiency
Volume 4 Issue 3 - 2018

\author{
Zamani A,' Ali AA Jeddi,' Ramezanianpour \\ $\mathrm{AA}^{2}$ \\ 'Department of Textile Engineering,Amirkabir University of \\ Technology, Iran \\ ${ }^{2}$ Department of Civil Engineering, Amirkabir University of \\ Technology, Iran
}

\section{Correspondence: Ali AA Jeddi, Department of Textile Engineering, Amirkabir University of Technology, Tehran I59|4, Iran,Email ajeddi@aut.ac.ir}

Received: January 17, 2018 | Published: May 01, 2018

\section{Introduction}

Reinforcement cement-based composites by textile materials improve the tensile and flexural performances of them. Several researchers reported that the geometry of fabric influenced the mechanical behavior of such composites. When polymer matrixes reinforced with fabrics, in which the yarns do not maintain a straight geometry, a reduction in reinforcing efficiency was observed..$^{1-3}$ This concept may not be valid in cementitious composites, since the nature of interactions between the cement matrix and the fabric and individual yarns are more complex. ${ }^{3}$ Previous works showed that the geometry of fabric, yarn type fabrication methods can significantly influenced the flexural performance of cement composite. ${ }^{1,4}$ Enhanced bonding of a fabric was found to occur when a nonlinear geometry was induced in individual yarn by the fabric structure. Previous workers showed that increasing the mesh dimension and reducing bundle size in weft insert knitted fabric improve composite performance. ${ }^{5}$ Pre-tensioning the fabrics also has an effect on the flexural performance of cement-based composites. ${ }^{6}$ The impact behavior of such composites fabricate with pultrusion method was reported better than other fabrication methods; in this manner the PVA fabrics exhibited better efficiency compare with PP fabrics. ${ }^{7-9}$

The object of the present paper is to provide an overview of the effect of three warp knitting fabric structure with three mesh dimension on flexural and compressive performance of three kinds of matrixes (standard mortar, cement with 0.23 and 0.26 water cement ratios) reinforced with three kinds of knitted fabrics which produced with three mesh dimensions were examined.

\section{Experimental program}

The following variables were evaluated in the present study:

\section{Fabrics}

Two guide bar fabric structures in three different kinds were produced (i.e.; Voil 2 (V2), Voil 3 (V3), and Marquisette (Mq) on Karl Mayer Raschel machine with gauge 6needles per inch. The lapping movement of these fabrics is drawn in Figure 1. These fabrics were prepared in three different densities; high density (h), medium density (m) and low density (l) to make different mesh size. The geometrical characteristics of these fabrics are presented in Table 1. To normalize the fabrics weight, the weight ratio is defined as the weight per unit area of each fabric over the weight per unit area of the lightest fabric (the low density Marquisette). The mechanical properties of the consumed yarn to knit these fabrics are also measured with INSTRON machine (model 5566) with constant rate of elongation (CRE) and presented in Table 2.

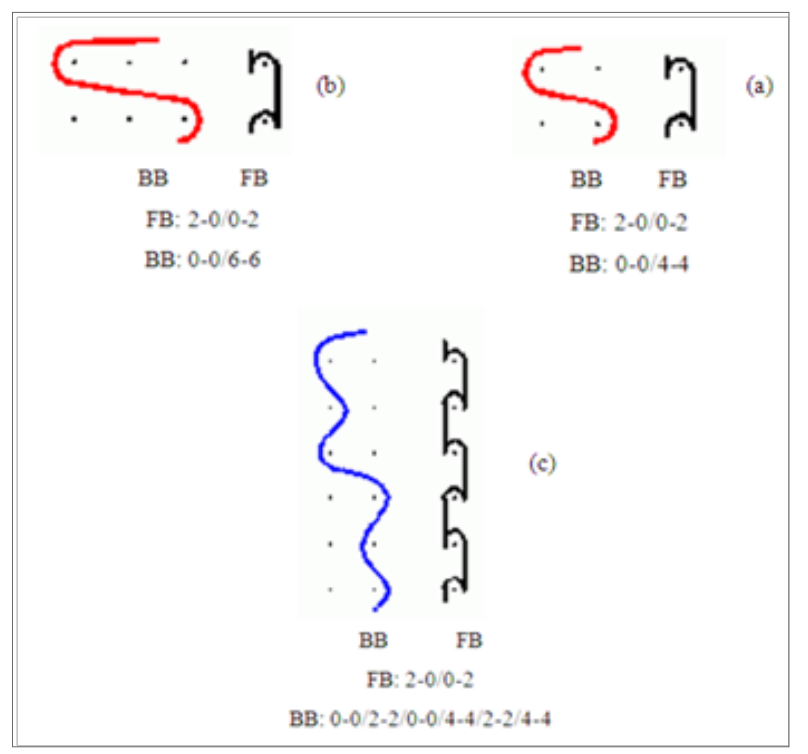

Figure I The different fabric types: (A) voil 2 fabric, (B) voil 3 fabric and (C) two guide-bar marquisette fabric. 
Table I Geometrical characteristics of the fabrics

\begin{tabular}{lllllll}
\hline $\begin{array}{l}\text { Fabric } \\
\text { structure }\end{array}$ & $\begin{array}{l}\text { Fabric } \\
\text { code }\end{array}$ & $\begin{array}{l}\text { CPC (Course per } \\
\text { centimeter) }\end{array}$ & $\begin{array}{l}\text { WPC (Wale } \\
\text { per centimeter) }\end{array}$ & $\begin{array}{l}\text { Weight } \\
\left(\text { gram } / \mathbf{m}^{2}\right)\end{array}$ & $\begin{array}{l}\text { Weight } \\
\text { ratio }\end{array}$ & $\begin{array}{l}\text { Mesh dimension } \\
\text { length } \times \text { width }(\mathbf{m} \times \mathbf{m})\end{array}$ \\
\hline Voil & $\mathrm{V} 2(\mathrm{~h})$ & 7.1 & 2.8 & 106.4 & 1.84 & $3.85 \times 1.52$ \\
Voil & $\mathrm{V} 2(\mathrm{~m})$ & 5.2 & 2.6 & 99 & 1.71 & $4.13 \times 2.06$ \\
Voil & $\mathrm{V} 2(\mathrm{l})$ & 5 & 2.3 & 95.3 & 1.65 & $4.71 \times 2.16$ \\
Voil & $\mathrm{V} 3(\mathrm{~h})$ & 8.4 & 3.2 & 148 & 2.56 & $3.34 \times 1.29$ \\
Voil & $\mathrm{V} 3(\mathrm{~m})$ & 6.7 & 3 & 122.6 & 2.12 & $3.61 \times 1.61$ \\
Voil & $\mathrm{V} 3(\mathrm{l})$ & 6.4 & 2.9 & 99.8 & 1.72 & $3.75 \times 1.69$ \\
Marquisette & $\mathrm{Mq}(\mathrm{h})$ & 9.6 & 2.2 & 84.5 & 1.46 & $4.81 \times 3.41$ \\
Marquisette & $\mathrm{Mq}(\mathrm{m})$ & 7.8 & 2.6 & 76 & 1.31 & $5.08 \times 4.24$ \\
Marquisette & $\mathrm{Mq}(\mathrm{l})$ & 5.4 & 1.8 & 57.9 & 1 & $6.00 \times 5.96$ \\
\hline
\end{tabular}

Table 2 Mechanical properties of the yarn used for fabrics

\begin{tabular}{|c|c|c|c|c|}
\hline Yarn type & Number of filament & Tenacity(cN/tex) (cN/tex) & Elongation(\%) at break & Yarn count (tex) \\
\hline Polypropylene & 65 & 30.18 & 38.56 & 47.5 \\
\hline
\end{tabular}

\section{Matrix types}

ASTM C 150 type 1 Portland cement was used in all matrixes. Chemical and physical characteristics of the clinker are shown in Table 3 . Three types of cementitious matrix were used: cement paste having 0.23 and 0.26 (w/c ratio) and ASTM standard mortar (the aggregate/ cement ratio was 2.75 having $0.485 \mathrm{w} / \mathrm{c}$ ratios). In the mortar matrix, the aggregate was natural sand. The aggregate has water absorption of $1.75 \%$ and a specific gravity of $2570 \mathrm{~kg} / \mathrm{m}^{3}$. The grading of aggregate according to the C33-03 standard is presented in Figure 2.

Table 3 Chemical and physical characteristics of clinker

\begin{tabular}{ll}
\hline \multicolumn{2}{l}{ Chemical components } \\
\hline Calcium oxide $(\mathrm{CaO})(\%)$ & 61.5 \\
Silicon dioxide $\left(\mathrm{SiO}_{2}\right)(\%)$ & 21.5 \\
Magnesium oxide $(\mathrm{MgO})(\%)$ & 4.8 \\
Aluminum Oxide $\left.\mathrm{Al}_{2} \mathrm{O}_{3}\right)(\%)$ & 3.68 \\
Ferric Oxide $\left(\mathrm{Fe}_{2} \mathrm{O}_{3}\right)(\%)$ & 2.16 \\
Sulphate Oxide $\left(\mathrm{SO}_{3}\right)(\%)$ & 2.5 \\
Potassium oxide $\left(\mathrm{K}_{2} \mathrm{O}\right)(\%)$ & 0.95 \\
Sodium oxide $\left(\mathrm{Na}_{2} \mathrm{O}\right)(\%)$ & 0.12 \\
Titanium oxide $\left(\mathrm{TiO}_{2}\right)(\%)$ & 0.04 \\
Phosphorus oxide $\left({ }_{\mathrm{p} 205}\right)(\%)$ & 0.23 \\
Lol $(\%)$ & 1.35 \\
\hline Mineralogical composition & \\
\hline $\mathrm{C}_{3} \mathrm{~S}(\%)$ & 51 \\
$\mathrm{C}_{2} \mathrm{~S}(\%)$ & 23 \\
$\mathrm{C}_{3} \mathrm{~A}(\%)$ & 55 \\
$\mathrm{C}_{4} \mathrm{AF}(\%)$ & 3.21 \\
\hline Physical characteristics & \\
\hline Blaine (m $3 / \mathrm{kg})$ & \\
\hline Specific gravity & \\
\hline
\end{tabular}

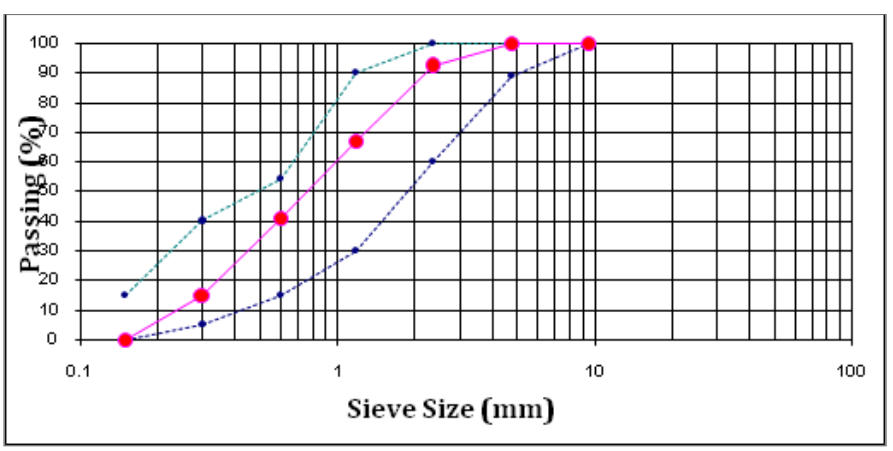

Figure 2 The grading of the fine aggregate.

\section{Composite preparation}

In order to keep the fabric parallel to the reinforcing axis during the preparation of the composite specimens, a tensile load must be applied on the fabric. Specimens with one layer of fabric were prepared by hand lay-up method. The dimensions of all specimens were $40-\mathrm{mm}$ in thick with length and width of 160 and $40 \mathrm{~mm}$, respectively.

During the preparation of the specimens an aggressive vibration was applied to achieve a better penetration of the matrix into the meshes of fabrics. After casting, the composite specimens were covered with a wet towel for $24 \mathrm{~h}$ and cured under laboratory conditions then they were demolded and cured in lime-saturate water at $23 \pm 2^{\circ} \mathrm{C}$ to prevent possible leaching of $\mathrm{Ca}(\mathrm{OH})_{2}$ from them.

\section{Experimental procedures}

The flexural properties have been investigated by three-point bending test which was carried out on Zwick's testing machine type 1494 at a cross-head rate of $1.2 \mathrm{~mm} / \mathrm{min}$. The load-deflection curves were recorded and the flexural strength of composite was also calculated. The test was ended up when the bridging fabric ruptured or the specimen split into two sides. Note that all tests were performed on the composite samples after 28days. 
Five parameters were defined and calculated from the results of these tests as following:

a. The flexural strength $(\partial)$, that can be calculated from Equation (1):

$$
\partial=\frac{3 \times F L}{2 \times b d^{2}}
$$

Where $\partial$ is the flexural strength $(\mathrm{Mpa}), \mathrm{F}=\operatorname{load}(\mathrm{N}), \mathrm{L}=$ length $(\mathrm{mm}), \mathrm{b}=$ width $(\mathrm{mm}), \mathrm{d}=$ thickness $(\mathrm{mm})$.

b. The toughness of the composite $(\tau)$, which is obtained by the calculation of the area under the load deflection curve up to the composite sample, is ruptured.

c. The flexural strength efficiency e $(\partial) \%$, which is defined as the ratio of the flexural strength value of the specimen over the flexural strength value of the composite reinforced with the lightest fabric (i.e. $\mathrm{mq}(1)$ ):

$$
e(\partial) \%=\frac{\partial \times 100}{\partial_{m q(l)} \times r}
$$

Where, $r$ is the weight ratio of each specimen (Table 2). d. The toughness efficiency $\tau \mathrm{e} \%$, is defined as the ratio of the toughness of each composite specimen over the toughness of the $\mathrm{mq}(1)$ composite specimen as shown in Equation (3)

$$
\tau e \%=\frac{\tau \times 100}{\tau_{m q(l)} \times r}
$$

e. The time of fracture or rupture of composites (T).

Compressive test were also carried out according to EN standard.

\section{Results}

\section{Mechanical properties of the composite}

The average value of flexural performances of composites, with cement paste matrix of $0.23 \mathrm{w} / \mathrm{c}$ ratio (water/cement ratio) is tabulated in Table 4. The matrix flexural strength was $13.385 \mathrm{kN}$ among the 43seconds. This table shows that the higher and lower performances in flexure is related to $\mathrm{Mq}(\mathrm{l})$ and V3 (h), respectively. From this table it can be also seen that the fabrics with low density exhibits higher flexural efficiency. The flexural behavior of the composites reinforced with V2 (h), V3 (h) and Mq (l) are also presented in Figure 3.

Table 4 Flexural performance of cement composites $(\mathrm{w} / \mathrm{c}=0.23)$

\begin{tabular}{llllll}
\hline $\begin{array}{l}\text { Specimen } \\
\text { code }\end{array}$ & $\begin{array}{l}\text { Flexural strength } \\
\text { (kN) }\end{array}$ & $\begin{array}{l}\text { Flexural strength } \\
\text { efficiency (\%) }\end{array}$ & $\begin{array}{l}\text { Rupture time } \\
\text { (s) }\end{array}$ & $\begin{array}{l}\text { Toughness (N } \\
\mathbf{m m})\end{array}$ & $\begin{array}{l}\text { Toughness } \\
\text { efficiency (\%) }\end{array}$ \\
\hline $\mathrm{v} 2(\mathrm{~h})$ & 15.17 & 54 & 230 & 5666 & 158 \\
$\mathrm{v} 2(\mathrm{~m})$ & 15.84 & 61 & 220 & 4892 & 147 \\
$\mathrm{v} 2(\mathrm{l})$ & 16.06 & 64 & 205 & 4312 & 134 \\
$\mathrm{v} 3(\mathrm{~h})$ & 14.5 & 37 & 330 & 8626 & 173 \\
$\mathrm{v} 3(\mathrm{~m})$ & 14.5 & 45 & 290 & 6854 & 166 \\
$\mathrm{v}(\mathrm{l})$ & 14.94 & 57 & 240 & 5397 & 161 \\
$\mathrm{Mq}(\mathrm{h})$ & 16.73 & 75 & 60 & 2343 & 82 \\
$\mathrm{Mq}(\mathrm{m})$ & 16.28 & 82 & 60 & 2143 & 83 \\
$\mathrm{Mq}(\mathrm{l})$ & 15.17 & 100 & 55 & 1942 & 100 \\
\hline
\end{tabular}

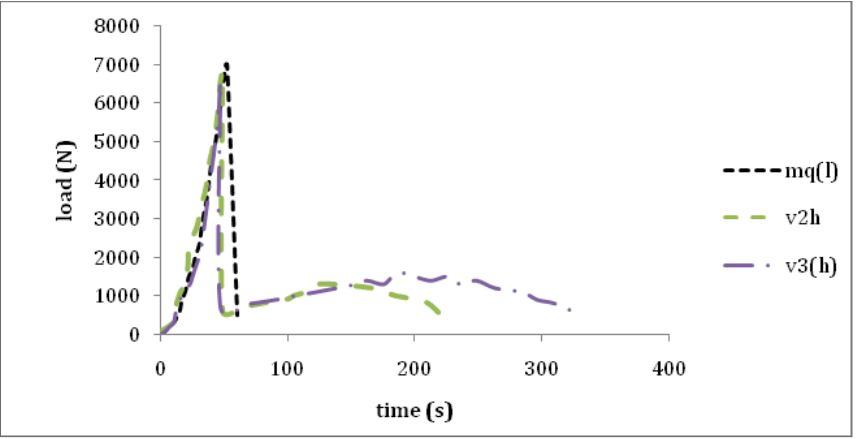

Figure 3 Flexural response of the cement $(w / c=0.23)$ composites reinforced with v2(h), mq(h) and v3(h) fabrics.

On the other hand when comparing the toughness of fabrics and its efficiency, the Voil 3 fabrics exhibited the highest toughness. In this case, the small mesh dimension has higher toughness efficiency unlike the flexural performance.
Table 5 compares the flexural efficiency of the composites with cement paste matrix of $0.26 \mathrm{w} / \mathrm{c}$ ratio. Matrix flexural strength was $12.716 \mathrm{KN}$ among the 39 seconds. In comparing between different cement paste matrixes ( 0.23 and 0.26 of water/cement ratio), similar trends can be observed.

The flexural efficiency and the toughness efficiency values of the different fabrics in composites with mortar matrix are shown in Table 6. The trends of these parameters are the same as the cement matrixes; however, the values of their toughness are higher than the cement matrixes. It should be noted that the mortar matrix flexural strength was $8.4375 \mathrm{KN}$ among the 40 seconds.

\section{Bonding and pullout characteristics}

The apparently contradictory trends observed in the flexural behavior of the fabric structure and different matrix may be related to the bonding between the different systems. ${ }^{1}$ This character can be evaluated by the pullout test; continuing the test after matrix fracture causes the fabric pulled and hence the bond characteristics were obtained comparatively. 
Table 5 Flexural performance of cement composites $(\mathrm{w} / \mathrm{c}=0.26)$

\begin{tabular}{|c|c|c|c|c|c|}
\hline $\begin{array}{l}\text { Specimen } \\
\text { code }\end{array}$ & $\begin{array}{l}\text { Flexural strength } \\
(\mathbf{k N})\end{array}$ & $\begin{array}{l}\text { Flexural strength } \\
\text { efficiency (\%) }\end{array}$ & Fracture time (s) & Toughness (N mm) & $\begin{array}{l}\text { Toughness } \\
\text { efficiency (\%) }\end{array}$ \\
\hline v2(h) & 14.277 & 53 & 245 & 5707 & 161 \\
\hline $\mathrm{v} 2(\mathrm{~m})$ & 14.277 & 57 & 230 & 5090 & 154 \\
\hline $\mathrm{v} 2(\mathrm{l})$ & 14.5 & 60 & 210 & 4393 & 138 \\
\hline v3(h) & 13.162 & 35 & 350 & 8699 & 175 \\
\hline $\mathrm{v} 3(\mathrm{~m})$ & 13.385 & 43 & 305 & 6886 & 168 \\
\hline v3(l) & $|3.83|$ & 55 & 260 & 5714 & 162 \\
\hline$M q(h)$ & 15.616 & 74 & 60 & 2042 & 72 \\
\hline$M q(m)$ & 15.17 & 80 & 58 & 2013 & 79 \\
\hline $\mathrm{Mq}(\mathrm{l})$ & 14.5 & 100 & 55 & 1876 & 100 \\
\hline
\end{tabular}

Pullout fabrics in cement and mortar matrixes composites

The estimated residual tensile strength of fabrics in the composites can be drawn from the load deflection curves. For this purpose, the residual tensile strength of fabric after matrix fracture can be considered as the estimated pullout load or the residual tensile strength of fabrics (Figure 3). The time of composites fracture are also shown in Tables 4-6. The results of time fracture show that, it is shorter for the marquisette fabrics than voil fabrics. Also, this parameter is much higher for the case of mortar matrix than the cement matrixes. Generally, the fabrics with higher density in all cases of matrixes have more rupture time. Finally, the rupture time of the high density voil 3 with the mortar matrix is more than the others.

Table 6 Flexural performance of mortar composites

\begin{tabular}{|c|c|c|c|c|c|}
\hline $\begin{array}{l}\text { Specimen } \\
\text { code }\end{array}$ & $\begin{array}{l}\text { Flexural strength } \\
(\mathbf{k N})\end{array}$ & $\begin{array}{l}\text { Flexural strength } \\
\text { efficiency (\%) }\end{array}$ & Fracture time (s) & Toughness (N mm) & $\begin{array}{l}\text { Toughness } \\
\text { efficiency (\%) }\end{array}$ \\
\hline v2(h) & 14.277 & 54 & 245 & 5707 & 161 \\
\hline $\mathrm{v} 2(\mathrm{~m})$ & 14.277 & 57 & 230 & 5090 & 154 \\
\hline $\mathrm{v} 2(\mathrm{l})$ & 14.5 & 60 & 210 & 4393 & 138 \\
\hline v3(h) & 13.162 & 35 & 350 & 8699 & 175 \\
\hline $\mathrm{v} 3(\mathrm{~m})$ & 13.385 & 43 & 305 & 6886 & 168 \\
\hline $\mathrm{v} 3(\mathrm{l})$ & $|3.83|$ & 55 & 260 & 5714 & 162 \\
\hline $\mathrm{Mq}(\mathrm{h})$ & 15.616 & 73 & 60 & 2042 & 72 \\
\hline$M q(m)$ & 15.17 & 79 & 58 & 2013 & 79 \\
\hline $\mathrm{Mq}(\mathrm{l})$ & 14.5 & 100 & 55 & 1876 & 100 \\
\hline
\end{tabular}

\section{Compressive strength in composites}

The average values of compressive strength of the composites with cement and mortar matrixes and their control samples are presented in Figure 4 \& Figure 5, respectively. These figures show that with the increase of the fabric density the compressive strength is decreased especially in the case of cement paste matrixes. This fact may be related to the micro cracks that occur between the matrix and fabric interface. In general speaking, the reinforcement of cementbased materials causes a reduction in the compressive strength of the composites. However, this reduction in composites with cement paste matrixes due to more uniformity is much more than that of the mortar matrixes. 


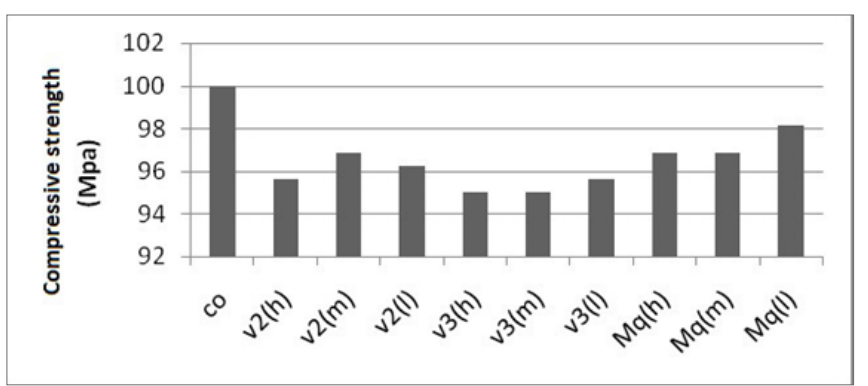

Figure 4 Compressive strength of cement composites $(0.23 \mathrm{w} / \mathrm{c})$.

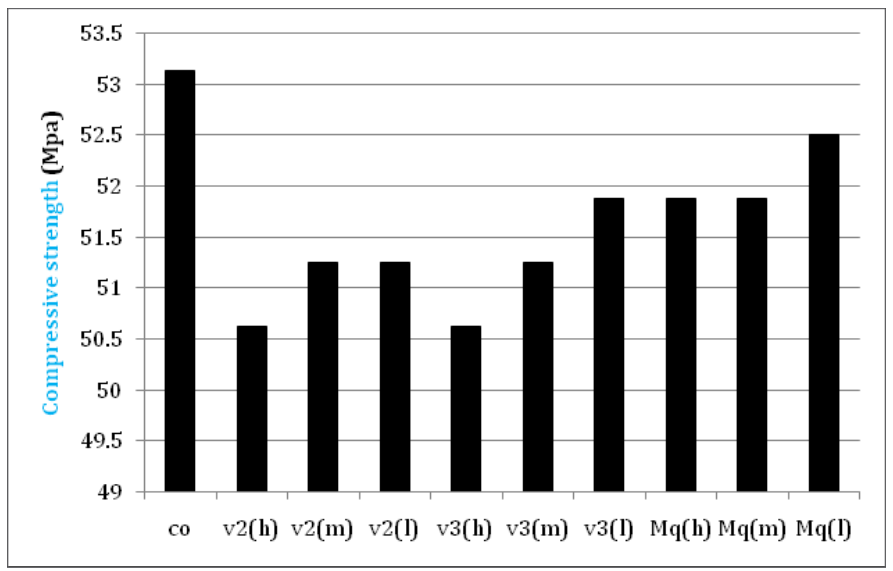

Figure 5 Compressive strength of mortar composites.

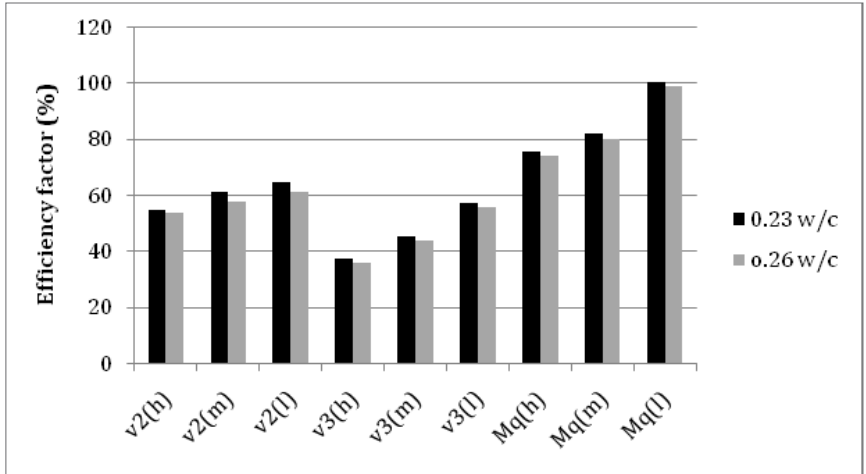

Figure 6 The flexural efficiency of fabric in cement composites with 0.23 and $0.26 \mathrm{w} / \mathrm{c}$ ratios.

\section{Discussion}

The geometry of fabric and the matrix characteristics showed a remarked effect on the mechanical properties of cement-based composites and the fabric efficiency as it was reported by the previous works. ${ }^{1-3,5}$

It should be kept in mind that the shape and size of the meshes in the various fabrics are different. In this research, the mesh size of the marquisette fabrics is larger than for voil fabrics. On the other hand, the shape of mesh in marquisette fabrics can be made as square or rectangle while, in voil fabrics only rectangle mesh shape is available. Such differences in fabric geometry may affect on the bond and mechanical performances of the composites. If the mesh size of the fabric is large enough so that the shear strength of the penetrated matrix in one mesh is higher than the tensile strength of the reinforced yarn, the size of the mesh can be acceptable. For these reasons, the marquisette fabrics was found to appear a higher flexural strength efficiency rather than voil fabrics (Figure 6) due to their more suitable mesh size and mesh shape (square mesh). It is clear that, for the matrixes with the coarser aggregates (such as mortar matrix); the used fabric mesh size should be larger to penetrate the courser aggregates through the meshes easily.

On the other hand, by considering the toughness and the toughness efficiency of the composites it was found that small mesh dimensions of the reinforcement exhibit a higher performance. This phenomenon can be attributed to the tensile strength of the used fabrics which is not influenced on the flexural strength of the composites. In fact, the used fabric has the role of a bridge over the composite's crack during its fracture and causes the specimen does not rupture immediately. Therefore, the fabrics with higher tensile strength exhibit a more toughness performance. For this reason the dense fabrics which have a higher weight ratio such as V3 (h) (with 2.56 weigh ratio) shows a more toughness value than the others. However, this kind fabric shows very lower strength efficiency as the reinforcement of the composite than Marquisette fabric. Thus, it can be concluded that to increase both flexural strength and toughness performances simultaneously, we have to use Marquisette structure due to its suitable geometry (mesh shape and mesh size) with higher weight. Consequently, we suggest using longer lapping movement in back guide bar or the three guide bars marquisette fabric which has similar geometry to two guide bars Marquisette with higher weight which is controllable by changing its lapping movements in two back guide bars and fabric density.

\section{Conclusion}

In the present experimental research, the mechanical performance of cement-based composites by textile material reinforcement was investigated. Marquisette and voil structures of two guide bars warp knitted fabrics in three different densities (low, medium, and high densities) were used as reinforcement. Mortar, and cement with 0.26 and 0.23 water/cement ratio were chosen as matrix.

The following conclusions were pointed out:

i. Generally, the warp knitted fabrics in this work (Marquisette and voil) as the reinforcement of cementitous composites improve the flexural strength and toughness, but decrease their compressive strength.

ii. Marquisette structure as a reinforcement in the composites presents higher flexural strength than voil structure.

iii. The denser fabric shows higher tensile strength which causes a more toughness value and has more rupture time than the lighter one.

iv. Cement matrix has much higher flexural strength than mortar matrix in all cases of the composites. In reverse, it has much less toughness and rupture time in comparing with mortar matrix.

v. Finally, it is suggested to produce the cementitious composites with higher performance i.e. higher flexural strength and toughness simultaneously, marquisette structure with longer lapping movement of back bar or three guide bars Marquisette structure should be used as the reinforcement material. 


\section{Acknowledgements}

None.

\section{Conflict of interest}

Authors declare there is no conflict of interest in publishing the article.

\section{References}

1. Peled A, Bentur A. Fabric structure and its reinforcing efficiency in textile reinforced cement composites. Composites part 1: Applied science and manufacturing. 2003;34(2):107-118.

2. Peled A, Bentur A. Geometrical characteristics and efficiency of textile fabrics for reinforcing cement composites. Cement \& Concrete Research. 2000;30(5):781-890.

3. Peled A, Bentur A, Yankelevskya D. Effects of woven fabric geometry on the flexural performance of cementinious composites. Advanced Cement Based Materials. 1998;7(1):20-27.
4. Peled A, Sueki S, Mobasher B. Bonding in fabric-cement systems: Effects of fabrication methods. Cement \& Concrete Research. 2006;36(9):1661-1671.

5. Peled A, Cohen Z, Pasder Y, et al. Influences of textile characteristics of warp knitted cement based composites. Cement and Concrete composites. 2008;30(3):174-183.

6. Peled A. Pre-tensioning of fabrics in cement-based composites. Cement \& Concrete Research. 2006;7(5):805-813.

7. Peled A, Mobasher B. Tensile behavior of fabric cement-based composites: Pultruded and cast. J Materials in Civil Engineering. 2007;19(4):340-348.

8. Gencoglu M. Effect of fabric types on the impact behavior of cement based composites in flexure. Materials \& Structures. 2009;42(1):135-147.

9. Peled A, Mobasher B, Cohen Z. Mechanical properties of hybrid fabrics in pultruded cement composites. Cement \& Concrete Composites. 2009;31(9):647-657. 